\title{
The Application of a New Kind of Ultrasonic Flow Meter in Industry 4.0 and Industrial Control Network
}

\author{
Haizeng Yan \\ Donghua University \\ College of Information Science and Technology \\ Shanghai Songjiang 201620
}

\author{
Jianli Zheng \\ Donghua University \\ College of Information Science and Technology \\ Shanghai Songjiang 201620
}

\begin{abstract}
Industry 4.0 is the definition of the new method of production made by academic circles and industrial circles. It is a revolution dominated by intelligent production, and has a broad developing prospect. But as a new thing, there are many difficulties in it. The development of industrial control network is on the basis of field-bus. It consists of a large number of measuring control instruments, what are scattered in the production site and have communication capacity. But products from different companies have different connection modes, so we need to choose a proper mode based on the situations in the field. As a general flow measuring instrument, flow meter has an important role in the automation and intelligentialize visualization of industrial production.
\end{abstract}

\section{Keywords}

Industry 4.0, Industrial control network, Flow meter

\section{INTRODUCTION}

People generally define the introduction of machinery manufacturing equipment in the 18th century as industry 1.0 , the electrification in the early 20 th century as industry 2.0 , the automation of production process, which began in $1970 \mathrm{~s}$, as industry 3.0, and the internet of things and the manufacturing services ushered in the fourth industrial revolution led by intelligent manufacturing, which people call industry 4.0 [1]. Industry 4.0 aims to make full use of information communication technology and cyber physics system (CPS), to make the manufacturing industry intelligentized.

The development of industry 4.0 needs the support of industrial control network. The development of industrial control network is on the basis of field-bus. It consists of a large number of measuring control instruments, what are scattered in the production site and have communication capacity [2]. Industrial network has a very high openness, and its requirement for communication protocols is high. It makes the communication between the equipments easier and faster.

\section{SYSTEM DESIGN PRINCIPLE}

\subsection{Design Idea}

Flow, temperature and pressure are the three most important parameters to the modern industry, so flow meter has a pivotal position in industry 4.0 and industrial control network. In order to implement the intelligent of the production, the flow meter also need to improve. Industrial control network has many characteristics. It realizes the transmission and communication of information, with connecting the equipments and systems; the system has openness, it can connect with other equipment which abides the same standard; at the same time, industrial control network can work with infrared, power lines, coaxial cable, and so on, which gives it the ability to adapt to different site environments; in the end, the communication is real-time. As a node, the flow meter must have a strong ability of data transmission. On the basis of the general flow meter, we can connect it with a small tablet PC, then the data transmission via the internet will significantly improve the liquidity of data.

\subsection{The Principle Of Time-Different- Type Ultrasonic Flow Meter}

The basis of time-different-type is the superposition of the speed of ultrasonic and the speed of fluid. For example, we take a ship on a river, even if the speed of the ship stays the same, but because of the speed of water, the speed of ship will be different when we go downstream and upstream. When we go downstream, the speed is faster than the speed of the ship, and when we go upstream, the speed is slower than the speed of the ship. So if the distances are the same, then the time of these two methods will be different, and the difference between the two is related to the velocity of the water [3]. As shown in fig 1 , the working principle of time-difference-type ultrasonic flow meter is similar to taking a ship.

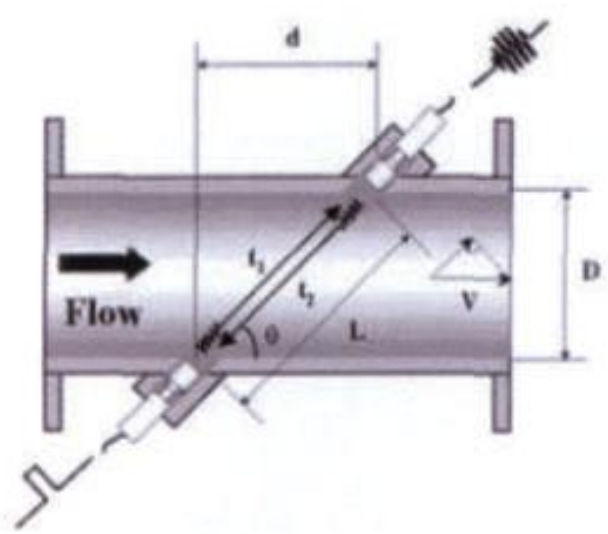

Fig 1: the measuring principle of time-different-type The times of the two methods are

$$
\begin{aligned}
& t_{1}=\frac{\mathrm{L}}{\mathrm{c}+\mathrm{V} \cos \theta} \\
& t_{2}=\frac{\mathrm{L}}{\mathrm{c}-\mathrm{V} \cos \theta}
\end{aligned}
$$

The difference between $t_{1}$ and $t_{2}$ is 


$$
\begin{aligned}
\Delta t=\mathrm{t}_{2}-\mathrm{t}_{1} & =\frac{\mathrm{L}}{\mathrm{c}-\mathrm{V} \cos \theta}-\frac{\mathrm{L}}{\mathrm{c}+\mathrm{V} \cos \theta} \\
& =\frac{2 \mathrm{VL} \cos \theta}{\mathrm{c}^{2}-\mathrm{V}^{2} \cos ^{2} \theta} \\
& =\frac{\frac{2 \mathrm{Vd}}{\mathrm{c}^{2}}}{1-\left(\frac{\mathrm{V}}{\mathrm{c}}\right)^{2} \cos ^{2} \theta}
\end{aligned}
$$

In general, $\mathrm{V}$ is much smaller than $\mathrm{c}$, so we can get

$$
\Delta t=\frac{2 \mathrm{Vd}}{\mathrm{c}^{2}}
$$

Then we can know

$$
V=\frac{\mathrm{c}^{2} \Delta t}{2 d}
$$

\subsection{System Frame Diagram}

As shown in fig 2, the ultrasonic flow meter has four most important parts: two ultrasonic transducers, a TDC-GP21 module, a MCU and a tablet PC.

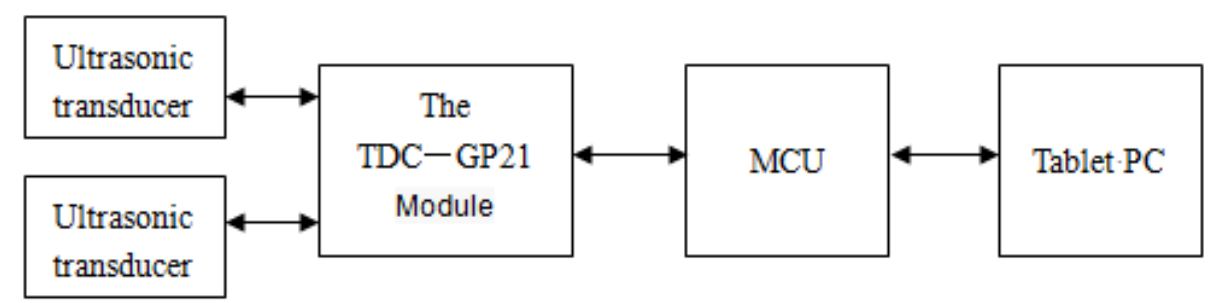

Fig 2: the system frame diagram of ultrasonic flow meter

\section{SYSTEM FUNCTION MODULE}

\subsection{Ultrasonic transducer}

Ultrasonic transducer is the sensing device of the system. Its function is to carry out the exchange of energy. In this system, we need a transducer, which can carry on the transformation between the electric energy and the sound energy [4]. Its performance directly affects the result of the measurement. As shown in fig 3, (a) is the equivalent circuit of series connection of piezoelectric ceramic transducer and matching inductor, and (b) is the equivalent circuit of resonant transducer [5].

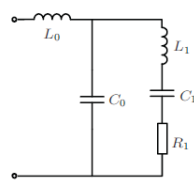

(a)

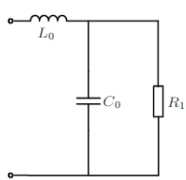

(b)
Fig 3: the circuit model of ultrasonic transducer

\subsection{The TDC-GP21 module}

As a time-difference-type ultrasonic flow meter, the measurement of time of ultrasonic propagation is the most important part. Its accuracy will affect the accuracy of the flow meter. For example, when ultrasonic waves in the water, its velocity is $1450 \mathrm{~m} / \mathrm{s}$, if the distance is $1 \mathrm{~m}$, then the travel time of ultrasonic is only $689.655 \mu \mathrm{s}$. So in general, the time difference is very small, only a few hundred nanoseconds, no more than a few microseconds. So there are high requirements for the measurement of time [6]. In this system, we use chip TDC-GP21 to accomplish this task. The peripheral circuit of the chip has been shown in fig 4 .

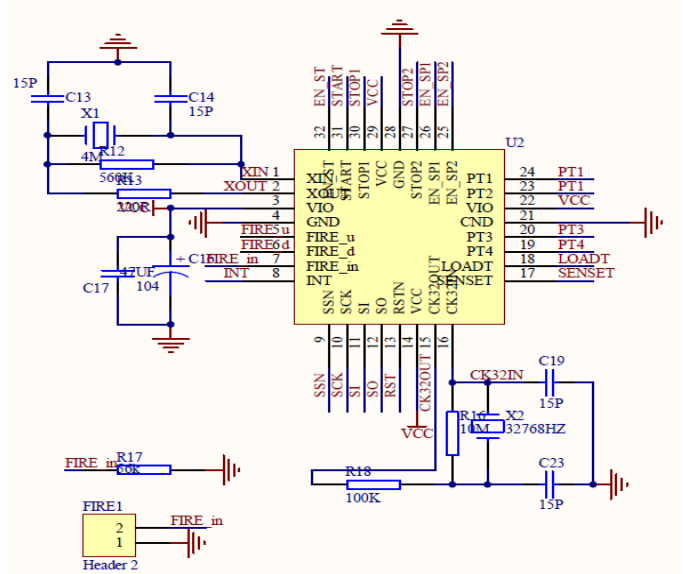

Fig 4: The peripheral circuit of the chip TDC-GP21

\subsection{The MCU}

The MCU has two functions: one is to control the TDCGP21 module, to get the time difference; the other is to transfer the result of the operation to the tablet PC. Its circuit diagram is shown in fig 5 .

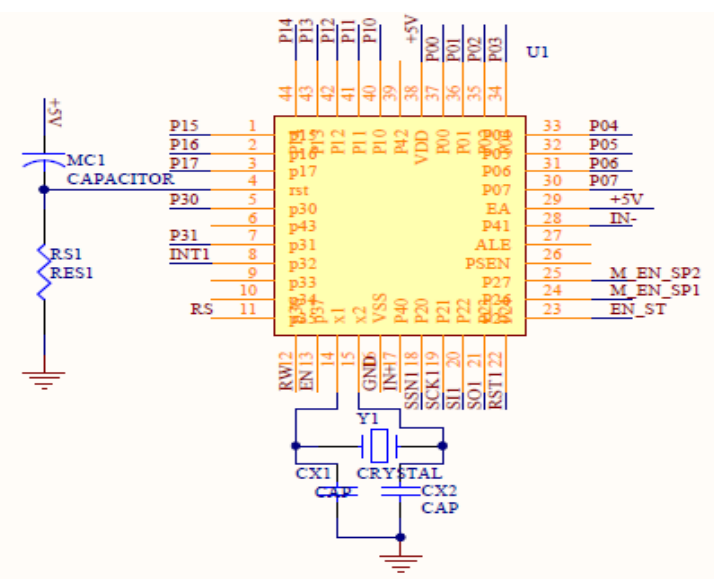

Fig 5: The peripheral circuit of the MCU 


\subsection{The tablet PC}

The measurement of flow velocity has little to do with the tablet PC, but its most important function is to make the flow meter networked and provide more human-computer interaction. The block diagram of the tablet PC is shown in fig 6 .

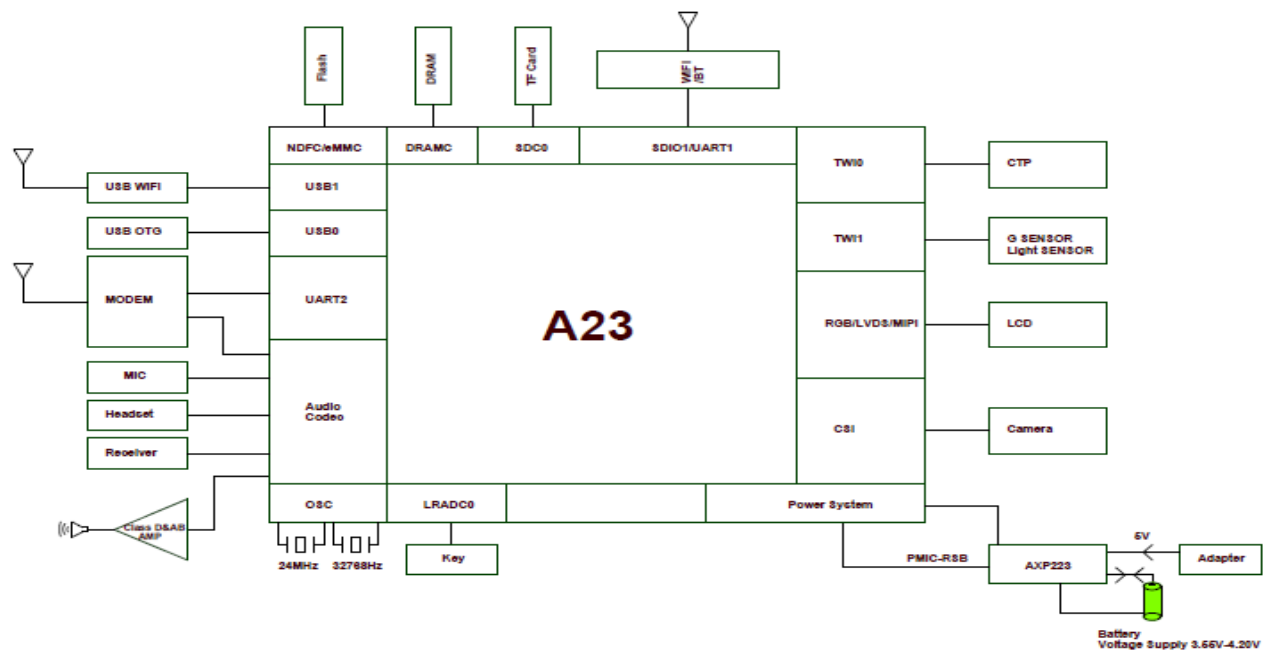

Fig 6: the block diagram of the tablet PC

\section{THE DESIGN OF SYSTEM SOFTWARE}

In order to achieve the intended function, we still need suitable software. As shown in fig 7, when the APP is opened, the tablet PC begin to get data from the MCU, then compare with the upper and lower limits. If the data is within the range we set, then save and send the data, and get the next data. If not, the tablet PC will raise the alarm, then save and send the data, and get the next data.

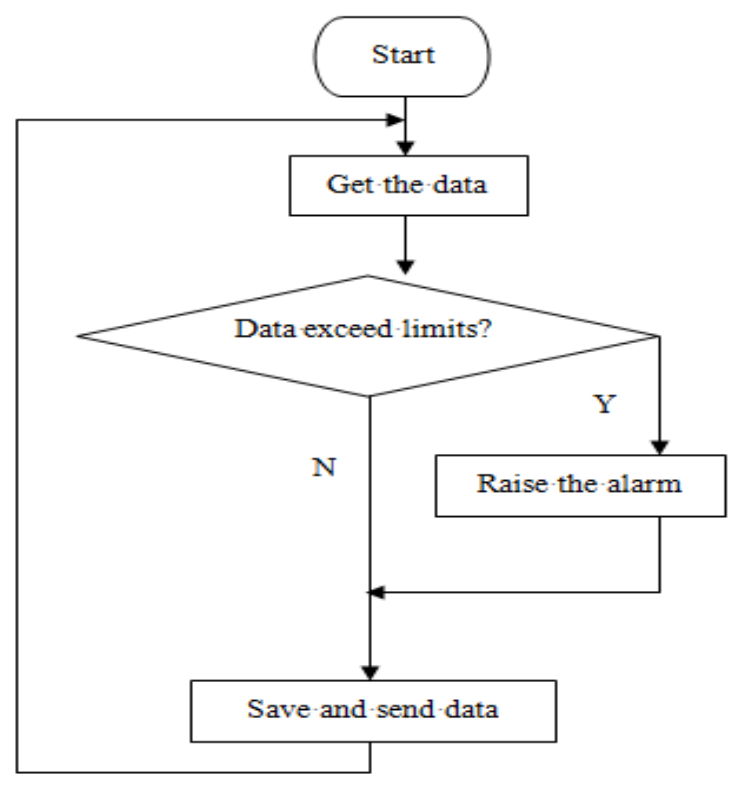

Fig 7: the flow chart of the system

\section{CONCLUSION}

On the basis of general ultrasonic flow meter, we add a tablet PC.

The new flow meter can bring about the transmission of data in the internet. Nowadays, with the coming of industry 4.0, virtual space and physical reality is continuously integrating in industrial production [7].
Traditional sensor must advance with the times, and begin to integrate with the internet. Wireless network is the development trend of industrial control network technology [8].

\section{REFERENCES}

[1] Shu Zhang. Industry 4.0 and intelligent manufacturing [J]. Machine Design and Manufacturing Engineering, 2014, (8): 1 to 5 .

[2] Xinqiu Zhao. Development of industrial control network [J]. Automation \& Instrumentation, 2008, (4): $3,4,17$.

[3] Peng Zou, Chuanyu Lv, Fengming Li. Principle and design of time-difference-type ultrasonic flow meter [J]. Construction Science and Technology, 2012, (4): 88 to 89 .

[4] Liping Dai, Tao He. Design of utrasonic wave transducer structure $[\mathrm{J}]$. Jiangsu Electrical Apparatus, 2008, (4): 39 to 40.

[5] Xipeng Xiao, Jiasheng Zhang, Zuchao Liu. Design and implementation of ultrasonic transducer based on single chip microcomputer control [J]. Journal of Applied Acoustics, 2015, (2): 113 to 118.

[6] Hui Shao. Application of TDC-GP21 in ultrasonic flowmeter based on time difference method [J]. Modern Electronics Technique, 2012, (12): 134 to 136.

[7] Xiwen Wang. Industry 4.0: intelligent industry [J]. Internet of Things Technologies, 2013,(12): 3 to 6.

[8] Yi Hu, Dong Yu, Minglie Liu. Present research and developing trends on industrial control network [J]. Computer Science, 2010, (1): 23 to 27. 